\title{
Teacher Continuing Professional Development and Team-Working Competences: A Case Study From Italy
}

\author{
Chiara Urbani* \\ Ca' Foscari University of Venice, Dorsoduro 3246, 30123 Venice, Italy
}

Received: 26.03.2018, Accepted: 02.12.2019, Published: 24.08.2020

\begin{abstract}
Context: European policies describe the key role of teachers' Vocational Education and Training (VET) in improving students' learning outcomes. In order to improve teacher education, Organisation for Economic Co-Operation and Development (OECD) policies identify competency models as the main framework for understanding teacher professionalism and designing VET policies. By reinterpreting these models through the capability approach, this article aims to identify more relevant competences of preschool teachers in the public and private services of northern and central Italy.

Methods: The research began with a comparative analysis of VET policies for preschool teachers to outline more common competences used to define their professional profile. This led to the creation of a new, re-thought competency model used to design a quantitative survey to describe teachers' competences in preschool settings. The self-assessment questionnaire was built on the following competence areas: Management of educational and relational processes, teamwork and large-scale teamwork, networking and governance. The self-assessment questionnaire evaluated 65 preschool teachers' pre-acquired competences and development levels and those more desirable for the future (called "ideal" co.). The comparison of areas and their values reveals critical results, particularly related to teamwork competences at different levels.
\end{abstract}

*Corresponding author: chiara.urbani@unive.it 
Results: The study outlines the structure of preschool teacher professionalism based on "traditional" competences (e.g., educational relationships with children) and some "innovative" competences (e.g., networking and governance), which appeared to be more desirable in teachers' evaluations. However, the comparison of the data reveals that governance competences are better evaluated then teamwork co., introducing some hypotheses about the quality of relationships in the community of practice.

Conclusions: The research outlines how the competences emerging as relevant for teachers need to be better activated in professional settings to become strategically important. The results related to teamwork and governance competences focus on the importance of informal and extended learning contexts to teachers' socio-relational competence development. The organization of the school system needs to be re-thought and extracurricular competences need to increase to foster the generative development of informal learning communities at intra- and extra-school levels. According to the capability approach, the research reveals the extreme complexity of preschool teacher professionalism. For vocational education and training, its underlines the re-thinking of the preschool teacher profile as a co-designer of learning environments, which includes building formal and informal competences to foster communities of practice as a learning and generative process.

Keywords: Teacher Professional Development, Teacher Education, Teacher Training, Preschool Teacher, Competency Model, Agency, Vocational Education and Training, VET

\section{Agency and Teacher CPD}

The increasing attention of European vocational and educational policies on the issue of teacher Continuing Professional Development (CPD) results related to better support teaching and learning improvement and its efficacy (European Commission, 2007; Council of the European Union, 2009; European Commission et al., 2015). This is particularly so in preschool services, where education and care systems qualification appear more linked to the quality of teachers and assistants' professionalism (Urban et al., 2011; Peeters et al., 2016).

Many reports (Organisation for Economic Co-Operation and Development [OECD], 2009, 2013; Urban et al., 2011) underline how teaching professionalism cannot be described only in terms of technical competences (e.g., knowledge, methodological and didactic co.). On the contrary, the latter should be integrated with others that better support and enhance these skills, in addition to extending their sense and value (Urban et al., 2011).

Moreover, the analysis on teacher education and training policies (OECD, 2009, 2013) gives the possibility of highlighting the new role of informal learning contexts and their return on professional qualification, in a way to adapt and foster teacher practice to answer today's social challenges and their new educational needs. 
These education and training policies consider competency models as more relevant on professional teacher qualification. Some of them seem to be wary of other variables that affect more or less the efficacy of a professional education based on competency models. This particularly concerns preschool teacher professionalism because of the influence of other "dimensions"- such as learning environment quality, work conditions and cultural backgroundthese may affect competency activation.

As Costa (2012) noted, teacher CPD cannot be evaluated only by formal and institutional models for teacher education and training. In fact, they consider and understand competency models and their competences as teaching requirements, taking for granted the ability to read, further understand and make choices. However, the following points need to be considered: i. Teacher CPD does not necessarily coincide with the competence meaning; ii. Other elements must be taken into consideration to foster competency activation; iii. These elements appear strictly involved to effective conditions and opportunities, in school contexts, to take advantage of them.

Therefore, it appears necessary to integrate competency models with the capability approach as it focuses the evaluation of tools, conditions and really accessible opportunities to activate personal resources in a capability process that enable to qualify professional agency.

The research on preschool teachers' CPD wants to investigate the opportunity of the integration between competency models and capability approach, to support CPD and its connection with self-education and agency increase. The analysis of policies and capability models (Sen, 1999; Nussbaum, 2011) identify as conceptual fundamentals of the agency defining the following dimensions:

1. A process dimension, within professional competences have to be involved for their activation. Professionalism today stems from a set of knowledge, skills and values that are created through the interaction with socio-cultural environments in continuous evolution. In Lazzari's (2012) study on "Early Childhood Education and Care" (ECEC), teacher preschool professionalism is understood as an evolutionary dimension, strongly related to the individual capability process that takes place in ECEC "entire competent system" (Urban et al., 2011), that includes all of the educational stakeholders and social participants in the qualification of the processes.

2. A fulfilment dimension, within the individual assumes the responsibility of personal choices and objectives, as the strategies to better achieve them (Margiotta, 2012; Costa, 2012). Sen (1999) considers the capability process for personal agency as a development process of freedom of choice for goals achievement, which influence human structuring. Nussbaum (2011) describes essential functionings, as "states of being and doing", for human flourishing, clarifying how resources and competences turn from environmental factors to functionings' activation. 
3. A relation dimension, that recalls the importance of social participation and democratic negotiation on goals choice, in order to emphasize the common advantage and prevent self-referential and preferential criteria. In other words, competency activation has to take into consideration the discussion of main values and principles, to select effective strategies to better agree personal aims with social ones.

These process, fulfillment and relational dimensions concern conditions and opportunities, but also the freedom of choice activation to convert competences into practice efficacy, and development personal and professional agency. Sen (1999) states, sure enough, that individual ability to fulfill personal aims depends on not only the availability of conditions and opportunities, but most of all from personal ability to activate them for personal achievements and functionings enhancement (Nussbaum, 2011).

In other words, a CPD basically centered on skills and competences collection, without any reference to its activation dimensions does not seem to be able to satisfy the needs and challenges in today's educational contexts. In fact, teacher education and training have to support a strategic rise of activation dimensions to better improve professional practice as well as non-formal and informal learning contexts participation (European Centre for the Development of Vocational Training, 2014).

Therefore, investment on the development of activation dimensions coincides with the sense of the capability approach. This leads on to the need to identify the research question: Can the capability process qualification improve the competency practice? And so, how can competency and capability process together affect teacher CPD? Again, what are the elements that better qualify the capability process and competency activation to agency development?

\section{Competence and Capability Process}

This research will study how the capability process and competency activation contributes to improve professional agency and better qualify teacher CPD. This helps to re-define professional vocational and training policies and to re-design the organizational, management and institutional agreements that support teacher professionalism.

On agreeing with the theory of empowerment (Alsop et al., 2006; Alkire \& Ibrahim, 2007), it becomes necessary, on the one hand, to integrate competences and new elements for their activation, but on the other, it becomes very important to give more attention to conditions and opportunities really available—as "conversion dimensions" of Nussbaum (2011) - to make it as practicable as possible. In other words, even if the conditions/opportunities of professional efficacy appear strongly linked to organizational, management and institutional arrangements, the real focus of capability process goes on the freedom and personal capacity to choose the main personal goals and give the "shape to the action" (Costa, 2012) to better 
pursue them. Sen (1999) remind us that the real opportunities to convert competences in functionings come from the freedom/ capacity to select between different options of agency, as from the freedom/ capacity to convert the selected option into practice, carrying out and putting into effect those option as really achievable.

In order to more precisely define the agency capability process, the first step of the research will focus on the correlation between specific levels of pre-acquired competences and the corresponding levels of standard agency performance. By doing so, we will emphasize the strong importance of activation dimensions supporting effective pre-acquired competences practice, and its influence on teacher professional development as on training and organizational devices (e.g., learning communities building, and organizational development at school institution). This kind of process, and its significance-just like the meaning of flourishing, as Nussbaum (2011) imply —identify the teacher CPD in a "generative process" (Costa, 2015), so as to create a virtuous circle of positive effects and returns in terms of empowerment. This can be achieved not only for teachers involved in educational and school contexts, but also for external participants (stakeholders), holding technical, administrative and political posts, in addition to families, associations and third sector.

In second step, therefore, the link between competency activation and a "generative CPD" recalls the importance of informal and extended learning contexts, understood as the contribution of social collaborations and stakeholders' interaction (Raffaghelli, 2012) on selfdevelopment processes.

Through these research steps, we will define which specific dimensions would support better than others the professional agency activation, involving informal and extended learning contexts and extra-school environments. This allows the outlining of a new model of teacher CPD more substantial and credible than others based on competency acquired.

Finally, this research aims to take advantage of results on teacher CPD to stimulate the reformulation of political, institutional and regulatory frameworks really capable of supporting its qualification.

\section{The Research Tool}

The study on existing competency models led to the creation of a new model of competences addressing the professionalism of preschool teachers, in order to support the design of a specific self-assessment questionnaire which describe teachers' competences in preschool settings. The method consists of three steps:

1. Creating a new model of professional competences and a related questionnaire. The competences were selected and mapped by the researcher among those arising as strongly connected to the preschool teacher professional profile (European Commission et al., 2013, 2014; Peeters \& Lazzari, 2011; Urban et al., 2011). This led to the creation of a new com- 
petency model ("the model of professional competences") made up of 6 areas of competence with total of 22 competences inside (Table1). These areas are made up composed of: $a$. The management of educational processes with the child (REL); $b$. The relationship process with families (FAM); $c$. The team-working process at school group level (COL T.); $d$. The large-scale team-working process at the institutional level (COL A.); $e$. The networking process in school networks (NET); $f$. The governance process with local stakeholders (GOV). These last competences (networking and governance), emerge from CoRe report (Urban et al., 2011) as the most relevant in the composition of today's preschool teacher professional profile. The structure of the competency model constitutes the central reference for the creation of an original self-assessment questionnaire made up of different items, which require the teachers involved to self-evaluate pre-acquired competences, their desires for the future, the level of competency development achieved (Tessaro, 2012), and the types of learning involved (formal, non formal, informal), from which the contexts of education and training originate.

2. Quantitative research. The self-assessment questionnaire on professional competences involves 65 teachers from different preschool services as well as different background and in-service practice experiences in several regions of northern and central Italy. The analysis and processing of data discloses: $a$. The areas of coincidence between competences evaluated in terms of pre-acquisition and development; $b$. The areas of emergent criticality (e.g., in the intersection between pre-acquired competences and their development levels); c. The backgrounds of teacher practice training (Nussbaum, 2011; Mortari, 2010) mainly endorsing educational professionalism.

3. Qualitative research. The following step, not mentioned in this paper, regards a participatory observation (Trinchero, 2004) and reflexivity process (Schön, 1993; Mezirow, 1991) where teachers compare reported competences, some of which are expressed in school practice. This step of the research carries out the design of a self-development plan based on priorities choice, recorded by "school practice logbooks". 
Table 1: The new Model of Competences for Preschool Teachers (Urbani, 2016).

\begin{tabular}{|c|c|c|}
\hline $\begin{array}{c}\text { 1. Co of Management of } \\
\text { Educational Process } \\
\text { (with Child) } \\
\text { REL }\end{array}$ & $\begin{array}{c}\text { 2. Co of Management of } \\
\text { Relationship Processes } \\
\text { (with Families) } \\
\text { FAM }\end{array}$ & $\begin{array}{c}\text { 3. Co of } \\
\text { Team Working Processes } \\
\text { (at School/Group Level) } \\
\text { COLT. }\end{array}$ \\
\hline $\begin{array}{c}\text { (e.g. School planning, project design, } \\
\text { methodology, leaning assessment...) }\end{array}$ & $\begin{array}{c}\text { (e.g. communicative hold } \\
\text { responsable, inclusive Co) }\end{array}$ & $\begin{array}{c}\text { (e.g. reflective, creative coopera- } \\
\text { tive Co) }\end{array}$ \\
\hline $\begin{array}{c}\text { 4. Co of } \\
\text { Large-Scale Teamworking } \\
\text { Proceses } \\
\text { (at Institutional Leel) } \\
\text { COLA. }\end{array}$ & $\begin{array}{c}\text { 5. Co of Networking } \\
\text { (School Networks) } \\
\text { NET }\end{array}$ & $\begin{array}{c}\text { 6. Co of Governance } \\
\text { (Local Stakeholders) } \\
\text { GOV }\end{array}$ \\
\hline $\begin{array}{l}\text { (e.g. corganizational cooperation, } \\
\text { social empowerment, vision \& mission } \\
\text { awarness) }\end{array}$ & $\begin{array}{l}\text { (e.g.ressouce sharing,socio- } \\
\text { relational and political Co, } \\
\text { networking) }\end{array}$ & $\begin{array}{l}\text { (e.g. pedagogical awarness } \\
\text { creation, professional enrich- } \\
\text { ment, partnership set-up) }\end{array}$ \\
\hline
\end{tabular}

We then examine several results emerging from the questionnaire items, describe the competences self-evaluated by preschool teachers, and the environmental factors and conditions that influenced the answers provided.

\section{$4 \quad$ Analysis of Partial Data}

In the quantitative survey by questionnaire, we collected data from 65 preschool teachers located in several regions of northern and central Italy. They were selected according to criteria of maximum diversification between geographical and socio-cultural contexts, schools (public and private preschool services), and teacher long-service practice. For example, in the survey preschool teachers coming from national institutes, municipality services, private companies, parental associations located in different areas (big cities, suburbs, small towns, countryside, regions) were involved. According to the research record, the teachers involved must hold at least five years of school practice to meet the survey criterion of in-service and professional development.

The questionnaire is structured displaying a first part with teachers' personal data, followed by several items regarding their self-evaluation on: Pre-acquired competences (In your opinion, what are your personal pre-acquired competences?), the development levels of competences (What are their development levels?), their desires for the future (What competence is more desirable to you, in order to integrate it in your professional profile?), and the kinds of 
learning involved (Formal, non formal, informal) linked to their education and training settings (What were your initial training settings that help you to develop your competences?).

A first reading of data allowed us to identify the most critical areas of competences in professionalism of preschool teachers. The result is that the area of competence of Networking (NET 1, 2, 3) describes some of the more significant variations in teachers' responses (value of standard deviation from the average), informing on important differences in individual assessments of the development levels of competences.

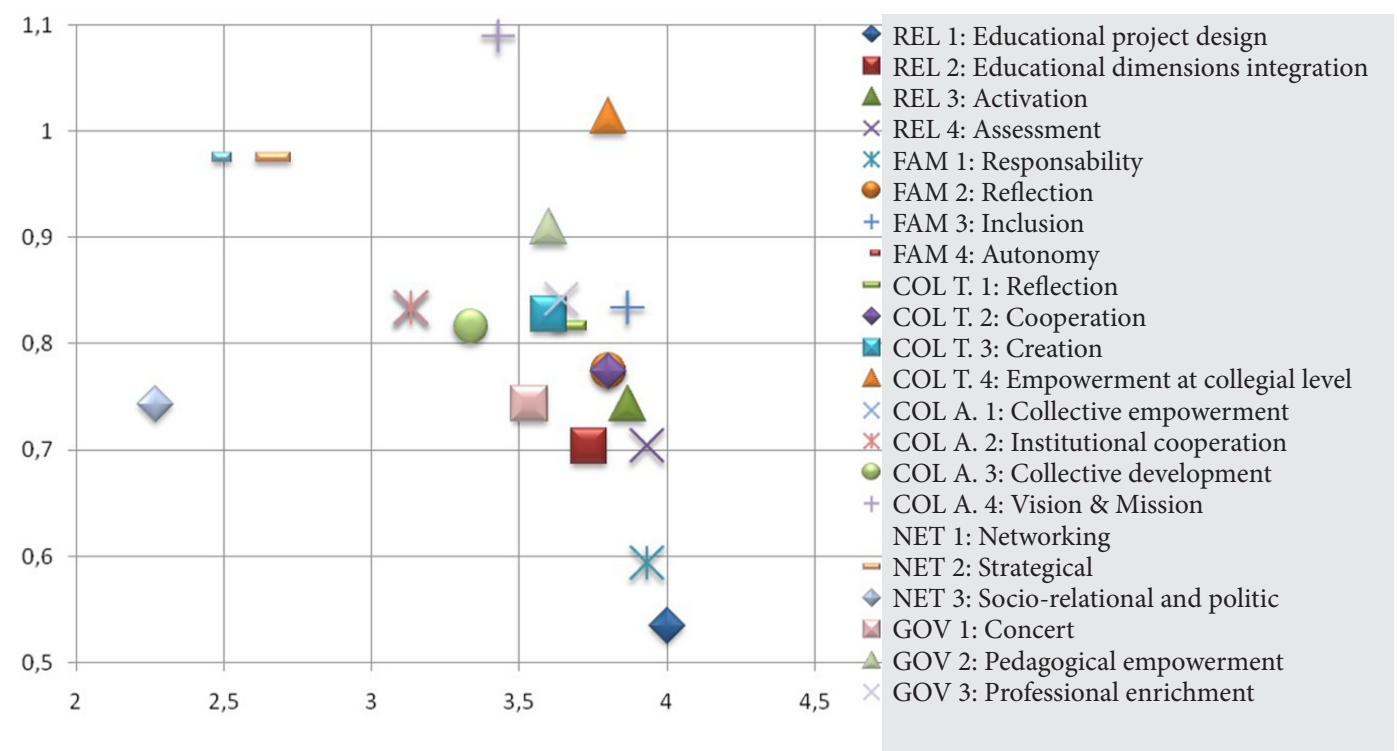

Figure 1: Development Levels of Competences

Note. Approximation of the relation between the average values of the levels of the competency development (horizontal axis) and the values of its standard deviation from the average (vertical axis) (Urbani, 2016).

Figure 1 shows the average value of the teachers' assessments and the standard deviation from this value. The most important results concern the competence of Vision and Mission (COL A. 4) in the area of collaborative competences in institutional cross-school levels. This competence is related to the ability to establish and enhance an institutional identity in its entirety, as well as the ability to jointly build the best course of action. Its value of standard deviation appears significant in comparison to the value of the average, informing on high level of discordance in teachers' evaluations (e.g., some evaluations are very "negative", whereas others are very "positive"). 
This evidence indicates how, in the area of networking competences, only a part of respondent teachers feel involved in an extended-levels collaborative process able to foster teachers' professionalism and support their action to affect professional community development and improvement.The data analysis focuses on the relevant differences between self-evaluated development levels of networking competences in the following areas: $i$. Cooperation as "ability to work in net"; (Networking competences, NET 1); ii. Ability to exploit the network opportunities in order to "strengthen and expand professionalism" (Strategic Networking competences, NET 2); iii. Ability to exploit the network action in order to "influence political decisions" (Socio- relational and Political Networking competences, NET 3).

The development level of these competences appears more variable-and interesting for us-than that of other competences typically assigned to the preschool teacher professional profiles, such as educational relationship competences (area of educational process, REL) or relationship with parents (area of related process with families, FAM). Overall, the development level of Networking competence in teacher responses shows a high variability in terms of standard deviation, and quite a low value of average. These results help to identify the area of Networking competence as the most critical in all the 6 areas comprehensively evaluated.

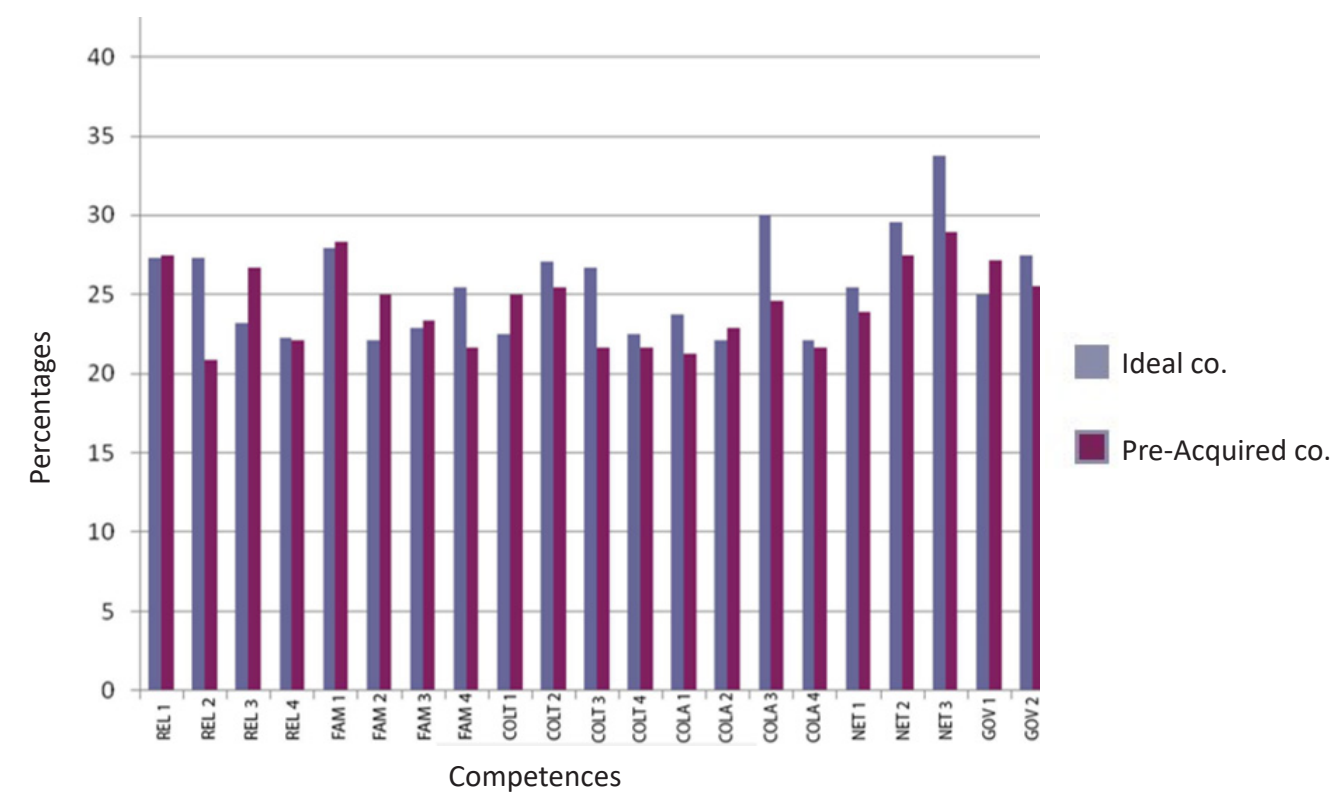

Figure 2: Ideal and Pre-Acquired Competences

Note. Comparison between the values of ideal and pre-acquired competences (Urbani, 2016). 
Figure 2 describes the comparison between pre-acquired competences and ideal ones too (these last, understood as what teachers wish to achieve in the future, in terms of CPD). The graph points out the existence of a greater gap within the Governance area of competence, referring to extracurricular planning and joint collaboration in local community with the educational stakeholders, to reach common goals. A first analysis of the comparison between pre-acquired competences and ideal ones inform us about an important increase of the value assigned to the Governance competences in the professional profile, for both pre-acquisition and ideal too.

Additional levels of analysis and data processing will make it possible to compare teacher's evaluations on these "new" Networking and Governance competences and more traditional ones. In fact, the former appear essential to support and qualify the development of the latter. In other terms, these socio-relational competences (Networking and Governance) that we can call a sort of "complex competences" of professional interaction: What kind of requirement do they take advantage of, and how can they act on CPD to a generative process?

\section{The Processing of Quantitative Data}

The final assessment and analysis of the 65 questionnaires reveal interesting tendencies in the socio-relational and cooperative competences that influence teachers' CPD. Moreover, these tendencies suggest some notable implications in terms of adult education.

Figure 2 illustrates the final comparison between the levels of pre-acquired and ideal competences. For those pre-acquired, the final analysis confirms that the main competences teachers self-evaluated are those of Governance called "Concert" competences (GOV 1, referring to the capacity for project and activities implementation with different stakeholders of the local community), and Educational Project Design (REL 1, into Area of Educational Process, referring to the ability of educational and curricular project designing and planning).

The ideal competences most recurrent in teachers' responses (e.g., what teachers desire even more) is part of the area of Governance (GOV 3, referring to the ability of personal enrichment through extracurricular planning and collaborative interaction with social stakeholders of the local community that hold educational returns).

The most critical competence evaluated, however, concerns the area of School Team collaboration and cooperation (COL T. 2, referring to the capacity for team working within groups of teachers). This specific point reveals a significant discrepancy between a low evaluation in the "pre-acquired" item and a high evaluation of the "ideal" one.

This result suggests the existence of a certain level of instability in team working competences, in direct opposition to a relevant tendency of deeming those abilities desirable and essentially fundamental in teacher professional profile. But even more so is the answer: How is it possible that teachers state they have only few competences, lacking those in team wor- 
king area at school level, and declare having the best in the area of extended collaboration with extra-school stakeholders at the same time?

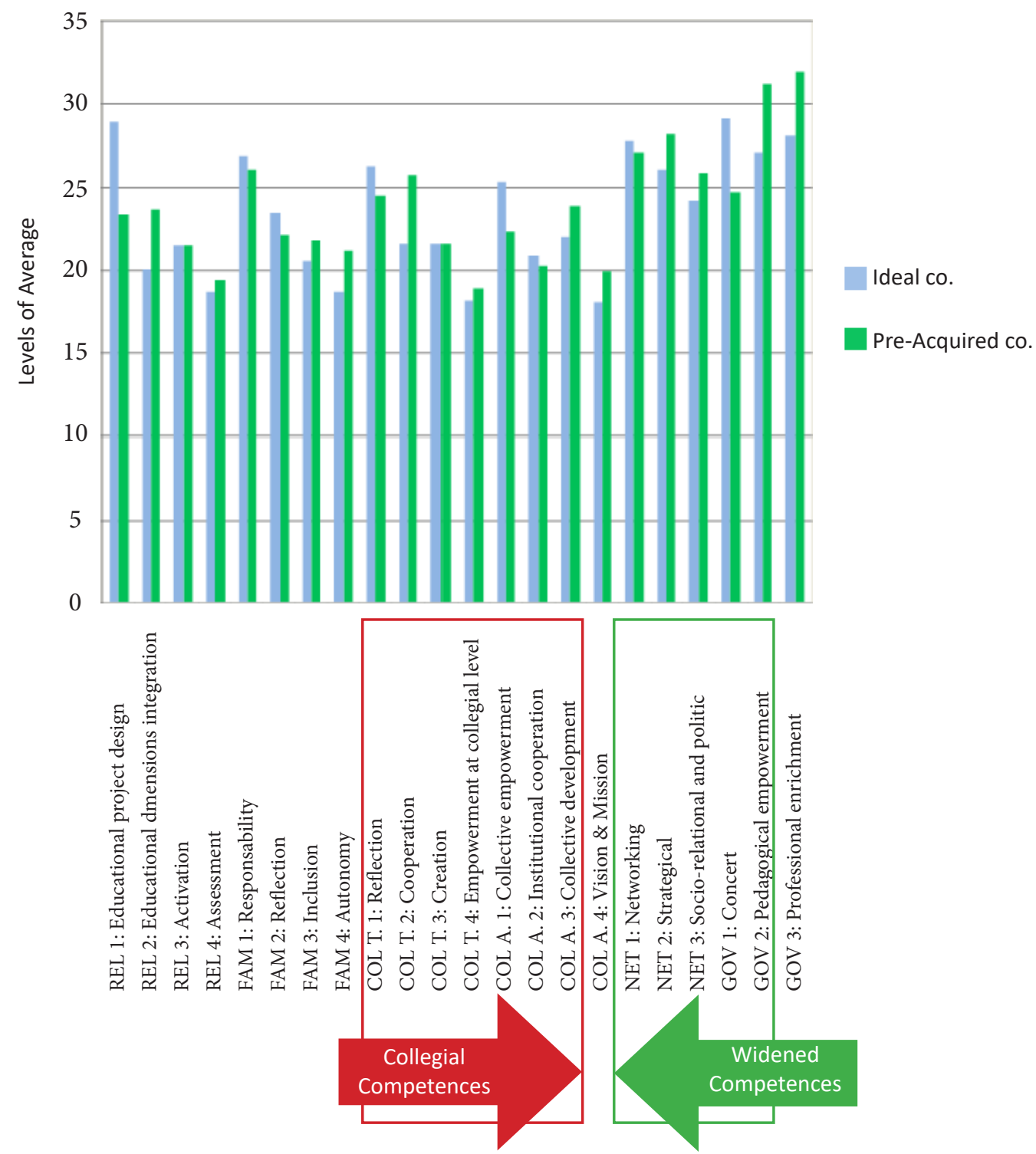

Figure 3: Final Results of Pre-Acquired and Ideal Competences

Note. Comparison of the final results into the levels of pre-acquired and ideal (in term of more desirable) competences (co.) of teachers (Urbani, 2016). 
The crucial piece of evidence, however, emerges from the graph in Figure 3, which shows the development level of those competences that in figure 2 showed only pre-acquisition and desirability. Teachers highly evaluated their Governance and Networking competences, whereas collaborative competences in team working showed a lower evaluation. Indeed, a more consequential result would have been a higher evaluation granted to collaborative competences within educational professionals with the same type of functions, and holding similar responsibilities (that is, between teachers). On the contrary, the respondent teachers seem to compare themselves to professions that are quite- or even strongly- different (e.g., not having intra-school roles and functions).

In general, the quantitative survey highlights that the development levels of competences (of those pre-acquired as well as ideal too) progressively become increasingly weaker compared to the more traditional competences (regarding, e.g., educational, didactic and practical work) reaching those socio-relational ones, as are collegial and collaborative (for example, team-building, communicational and cooperative competences). Also, while in the area of Related process with families (FAM) the evaluation of teachers produced positive responses, the evaluations with school team collaboration competences (COL T.) worsened. Finally, development level of collaborative Cross-school competences (COL A.) and Networking ones (NET) received the lowest evaluation. Scores only increased with the Governance competences (GOV).

Therefore, we find ourselves facing the paradoxical situation in which Governance competences receive better evaluation than the Team working ones. That is, teachers prefer joint collaboration and social interaction with educational stakeholders of the local community, and/or extra-curricular professionals more than team working collaboration and decisionmaking amongst professionals who are placed in the same school, sharing the same issues, problems and working conditions.

The development of Governance competences does not appear linked to a kind of formal initial teacher education, or to a pedagogical and theoretical pre-acquisition competence. On the contrary, the Governance competences result as those related to an informal learning dimensions in extra- curricular and extra-institutional contexts. Tracing a correlation with cross-section sample elements, we can notice that the respondent teachers did not hold high initial training levels: Only $20 \%$ of them hold an academic training profile (which, sometimes, is not considered coherent with the professional profile). Therefore, we presume that teachers involved would appoint an informal origin also to other competences, that teachers of other school levels have reached with a formal initial education. At the same time, however, it should be noted that all the initial training pathways of preschool teachers, from high school level to academic education, are lacking in contents related to Networking and Governance competences. 
The relevant difference in evaluations in Vision and Mission competences (Figure 1) suggests a likely connection with the double focus on the professionalism of teachers (on the one hand, traditional Educational competences related to formal training; on the other hand, Governance competences and their informal training implications). In other words, teacher professional agency involves both traditional competences and more innovative ones in a capability process that request the qualification of the intra-school relationship process, both at a team working level and an institutional one.

The most interesting evidence emerging from the quantitative survey, however, is the low evaluation of school collaborative competences (team working competences, COL T). As we have seen, this data indicates that teachers better evaluate a kind of "external" professional competence, rather than one more related to teaching professionalism. But the fact that team working competences (Figure 2) are considered highly desirable, despite being rather neglected in the previous questions of the survey, suggests the existence of a kind of awareness about the need to integrate them into teacher professionalism.

\section{Conclusions: Hypothesis of Professionalism Expansion}

The evolution of teacher professional requirements calls for a new investment in terms of capability process to find effective strategies and opportunities for CPD improvement (European Commission, 2017; European Commission et al., 2014). Far from a concept of work (and its professionalism) as being a functional and performative act, professionals today have to focus on the capability of process and fulfillment dimensions including socio-relational ones, in order to plan both personal and professional meaningful pathways (Costa, 2008, p. 271).

The topic of collaborative competences and learning communities among teachers still produce discussions in the international scientific community (Johnson \& Johnson, 1994; Hord, 1997; Vermette, 1998; Wenger, 2006; Alessandrini, 2007). In the survey, quantitative results on the variability of the development in team working competences of teachers lead to make their connection with formal and informal settings. As desirable as it may be, the increase of more "innovative" competences need a strong pre-acquisition of communicative and socio-relational competences. However, the importance of informal and extended learning contexts on socio-relational competence development endorses the re-thinking of the formal ones, such as schools and institutions of initial education and training. This goes back to the evaluation of the quality in formal settings, and about its educational and organizational choices. In other words, it would be necessary to evaluate in advance whether the above-mentioned system is able to face the much needed change, and to effectively support it (Costa, 2015, p. 181) or if this should be rethought at the source. The development of team working competences entails a radical re-thinking of the organization of the school system, 
as well as the need to increase extra-curricular competences, so as to foster and support the generative development of informal learning communities at extra-school level. Consequently, the following points need to be taken into consideration:

- The re-thinking of the learning environment. School spaces, both physical and mental, must become qualifying environments where learning opportunities and skills can be activated, fostering real and professional development. The capability process on professional agency depends on the availability of these opportunities and other, shared, collaborative and participative practices between teachers. This makes it possible to redefine priorities and pathways to better achieve teacher competences, and activate them in practice (Urbani, 2018).

- The school leadership qualification. It becomes necessary to identify the school manager as a transformer of the school culture: The investment on the development of conditions and opportunities for teachers to really achieve personal and professional goals would foster an authentic culture of autonomy. This challenges new organizational and management models able to include and empower educational governance.

- The definition of a systematic policy of teacher vocational and educational training. Sociorelational competences have to be supported in initial education and training pathways, and in teaching qualification courses. The insertion of communicative, cooperative, management, organizational, and strategic skills in teacher training curricula can foster a new awareness on self- determination and capability process in working and decisionmaking settings (Urbani, 2018).

The survey results indicate the increasing importance given to the extra-curricular dimensions of Networking and Governance. The quantitative data suggest new interpretations of the teacher role and function as an active agent of change and transformation, particularly in relations and process dimensions. This implies a reshaping of teacher professional vocational training and adult education, according to a model based on capability process. This, in turn, suggests new planning and project designing dimensions for social inclusion and collaboration (governance). It also points towards new policies and approaches in support of individual $\mathrm{CPD}$, thereby defining new vocational training pathways.

Critical issues regarding development levels of Networking competences suggest both an investment in the technological and infrastructural sector, as the building of networking cooperative agreements. The data collected thus far indicate a need to rethink the institutional, regulatory and organizational conditions, but also contractual ones too: New, real possibilities for teachers to meet each other and exchange different views in school practice should be 
created, at wider and extended levels. More than local community, these type of experiences, related to the professional competency development and activation, need to be formally recognized in terms of career advancement. For example, it is important to provide:

- Institutional, regulatory, contractual and organizational opportunities that are able to enhance and support communities of practice (Wenger, 2006); experiences of extended collegiality; new relational and planning contexts, at intra-curricular and extracurricular level.

- Contractual work guarantees that add new dimensions of professionalism (e.g., interaction with informal and extended learning contexts) to the definition of the professional profile. These additions should be combined by incentives and appropriate career plans.

- The existence of initial formal and informal training pathways, as well as in-service training courses, would allow teachers to come in contact with new realities and to experiment new personal activation opportunities. This approach would aim to determine the qualification of professionals who are capable of a team-working relationship with their peers, engaging and exchanging views in a socio-cultural context. These professionals would be able to face the problems and accept new challenges and create new opportunities for innovation with collective returns.

A substantial need for the requalification and redefinition of the professionalism of teachers at all levels, and its development is apparent.

On the one hand, the growing importance of reorganizing collaborative practices at school level will allow teachers to acquire new Team working competences, in order to efficaciously challenge themselves with extra-school contexts (in agreement with individual capability process). On the other hand, the insertion of new competences (such as the capability to manage extended learning contexts) will produce positive effects not just in terms of participation of these contexts (social capability process) but also, in turn, on the empowerment of efficacy and achievement of student outcomes. In fact, formal learning contexts will benefit from the improvement of the overall working climate, due to its capacity to positively reflect important aspects such as flexibility, openness and adaptation to changes. The growth of the socio-relational and collaborative working competences of teachers at school level requires a punctual assessment of the consequences both in terms of adult education and vocational training, as well as in social and democratic culture development. This, according to the following perspectives includes: 
- The rethinking of professional, vocational and training policies which must include informal aspects of extended learning contexts within learning communities (Krašovec et al., 2014).

- The redefinition of a new image of the teacher as a professional who is actively involved in co-designing the learning environment as an educational integrated system with inclusive importance (Ellerani, 2013).

- The support of reflexivity competences in collaborative practices will allow for the transfer of competences from the institutional level to an informal one, thereby stimulating community learning in terms of "learnfare" (Margiotta, 2012; Costa, 2012).

- The creation of communities of practice that hold political and pedagogic value, and are based on participatory processes and democratic negotiation, support social emancipation and the challenges of inequality (Sorensen \& Murchú, 2004).

\section{References}

Alessandrini, G. (2007). Comunità di pratica e società della conoscenza [Community of Practice and Knowledge Society]. Carrocci.

Alkire, S., \& Ibrahim, S. (2007). Agency and empowerment: A proposal for internationally comparable indicators. Oxford Development Studies, 35(4),379-403. https://doi.org/10.1080/13600810701701897

Alsop, R., Bertelsen, M. F., \& Holland, J. (2006). Empowerment in practice. From analysis to implementation. The International Bank for Reconstruction and Development/The World Bank. https://doi. org/10.1596/978-0-8213-6450-5

Costa, M. (2008). Politiche e professionalità per il lifelong learning. Milano: Bruno Mondadori [Policies and professionalism for lifelong learning. Milan: Bruno Mondadori]. Venice International University. https://hdl.handle.net/10278/29779

Costa, M. (2012). Agency formativa per il nuovo learnfare [Training agency for the new learnfare]. Formazione \& Insegnamento, 10(2), 83-107. Venice International University. https://hdl.handle. net/10278/36518

Costa, M. (2015). Capacitare lo sviluppo professionale e organizzativo del sistema scolastico [Capacitate the professional and organizational development of the school system]. Pedagogia Oggi, 2, 181-199. Venice International University. https://hdl.handle.net/10278/3664876

Council of the European Union. (2009). Council conclusions of 12 May 2009 on a strategic framework for European cooperation in education and training ("ET 2020"). Official Journal of the European Union, C119 of 28.05.2009, 2-10. Cedefop. https://www.cedefop.europa.eu/files/education_benchmarks_2020.pdf

Council of the European Union. (2014). Council conclusions of 20 May 2014 on effective teacher education.Official Journal of the European Union, C183, 14.6.2014, 22-25. EUR-Lex. https://eur-lex. europa.eu/legal-content/EN/TXT/PDF/?uri=CELEX:52014XG0614(05)\&from=EN 
Ellerani, P. (2013). Gli scenari educativi e formativi internazionali in mutamento: contesti cooperativi e capability approach [Changing international educational and training scenarios: Cooperative contexts and capability approach]. Formazione \& Insegnamento, 17-31. Venice International University. https://hdl.handle.net/11587/390495

European Centre for the Development of Vocational Training. (2014). Terminology of European Education and Training Policy (2nd ed.). Publications office of the European Union. https://doi. org/10.2801/15877

European Commission. (2007). Improving the quality of teacher education. Commission staff working document. Communication from the commission to the council and the European Parliament. https://app.parlamento.pt/webutils/docs/doc.pdf?path=6148523063446f764c324679626d56304c $334 \mathrm{e} 706447567 \mathrm{a} 4 \mathrm{c} 31684 \mathrm{~d} 5 \mathrm{a} 5763765130394 \mathrm{e} 4 \mathrm{c} 7 \mathrm{a} 684452554 \mathrm{e} 7762334 \mathrm{e} 535156497651584 \mathrm{a} 7864$ 576c3262304e7662576c7a633246764c314a6c6247463077374e796157397a4a5449775a5355794d464268636d566a5a584a6c6379394a546b6c46565649764d334e6c63334e68627938784d444d7655305644587a49774d4464664f544d785830564f5833426b5a6935775a47593d\&fich=S EC_2007_931_EN_pdf.pdf\&Inline=true

European Commission. (2017). School development and excellent teaching for a great start in life. Communication from the Commission to the European Parliament, the Council, the European economic and social committee of the regions. https:/eur-lex.europa.eu/legal-content/EN/ TXT/?uri=COM\%3A2017\%3A9\%3AFIN

European Commission, EACEA, \& Eurydice. (2013). Key data on teachers and school leaders in Europe. 2013 Edition. Eurydice Report. Publications Office of the European Union. https://doi. org/10.2797/91785

European Commission, EACEA, \& Eurydice. (2015). The teaching profession in Europe: Practices, perceptions, and policies. Eurydice Report. Publications Office of the European Union. https:// ec.europa.eu/eurydice

European Commission, EACEA, Eurydice, \& Eurostat. (2014). Key data on early childhood education and care in Europe. 2014 Edition. Eurydice and Eurostat Report. Publications Office of the European Union. https://doi.org/10.2797/75270

Hord, S. M. (1997). Professional learning communities: Communities of continuous inquiry and improvement. Southwest Educational Development Laborator.

Johnson, D. W., \& Johnson, R. T. (1994). Learning together and alone. Englewood Cliffs.

Krašovec, S. J., Radovan, M., Močilnikar, Š., \& Šegula, S. (2014). Older men Learning in urban and rural municipalities in Slovenia. In M. Radovan \& S. Jelenc Krašovec (Eds.), Older men learning in the community: European snapshot (pp.79-98). Ljubljana University Press.

Lazzari, A. (2012). Reconceptualising professionalism in early childhood education: Insight from a study carried out in Bologna. Early Years, 32(3), 252-265. https://doi.org/10.1080/09575146.201 1.651711

Margiotta, U. (2012). Dal welfare al learnfare. Verso un nuovo contratto sociale [From welfare to learning. Towards a new social contract]. In M. Baldacci, F. Frabboni \& U. Margiotta (Eds.). Longlife/ Longwide learning. Per un Trattato Europeo della Formazione. Pages? Mondadori.

Mezirow, J. (1991). Transformative dimensions of adult learning [Transformative dimensions of adult learning]. Jossey-Bass Inc.

Mortari, L. (2010). Dire la pratica. La cultura del fare scuola [Say the practice. The culture of schooling]. Mondadori. 
Nussbaum, M. (2011). Creating capabilities. The human development approach. The belknap Press of Harvard University Press. https://doi.org/10.4159/harvard.9780674061200

Organisation for Economic Co-Operation and Development. (2009). Creating effective teaching and learning environments: First result from Talis. OECD Publishing.

Organisation for Economic Co-Operation and Development. (2013). Education at a Glance 2013. OECD Indicators. OECD Publishing. https://doi.org/10.1787/eag-2013-en

Peeters, J., \& Lazzari, A. (2011). Quali competenze per i professionisti della prima infanzia? Le prospettive europee per l'innovazione e la formazione delle competenze nel lavoro educativo con la prima infanzia [What skills for early childhood professionals? European perspectives for innovation and skills training in early childhood educational work]. In Giacopini \& Ottolini (Eds.). Crisi Economia e Creatività Educativa: l'Innovazione inizia dal Nido. Esperienze Nazionali ed Europee a confronto (pp. 14-27). IUSVE Psichologye de l'Education. DOI/URL?

Peeters, J., Sharmahd, N., \& Budginaite, I. (2016). Professionalisation of childcare assistants in early childhood education and care (ECEC): Pathways towards qualification. NESET II report. Publication Office of the European Union.

Raffaghelli, J. E. (2012). Apprendere in contesti culturali allargati. Formazione e globalizzazione [Learning in wider cultural contexts. Training and globalization]. Franco Angeli.

Schön, D. (1993). The reflective practioner: How professionals think in action. Temple Smith.

Sen, A. (1999). Development as freedom. Oxford University Press.

Sorensen, E. K., \& Murchú, D. Ó. (2004). Designing online learning communities of practice: A democratic perspective. Journal of Educational Media, 29(3), 189-200. https://doi. org/10.1080/1358165042000283066

Tessaro, F. (2012). Lo sviluppo della competenza: Indicatori e processi per un modello di valutazione [Competence development: Indicators and processes for an evaluation model]. Formazione \& Insegnamento, 1, 105-119. Venice International University. https://hdl.handle.net/10278/35246.

Urban, M., Vandenbroeck, M., Peeters, J., Lazzari, A., \& Van Laere, K. (2011). CoRe final report. Competence requirements in early childhood education and care. A study for the European Commission Directorate- General for Education and Culture. University of East London. https://files.eric. ed.gov/fulltext/ED534599.pdf

Urbani, C. (2016). Capacitare lo sviluppo professionale docente. Oltre il valore della competenza [Capacitate the professional development of teachers. Beyond the value of competence] (Doctoral dissertation, Venice International University]. https://hdl.handle.net/10579/8322

Urbani, C. (2018). Lo sviluppo professionale docente dalle competenze alla capacitazione. Un modello per la prescolastica [Teacher professional development from skills to proficiency. A model for preschool]. Franco Angeli.

Vermette, P. J. (1998). Making cooperative learning work. Prentice Hall.

Wenger, E. (2006). Comunità di pratica. Apprendimento, significato e identità, Milano: Raffaello Cortina [Communities of Practice. Learning, Meaning and Identity]. Cambridge University Press. (Original work published in 1998). https://doi.org/10.1017/CBO9780511803932 


\section{Biographical Note}

Chiara Urbani, completed her doctorate in Educational and Cognitive Sciences in 2016 at the Ca' Foscari University of Venice, Italy. Since 2012 she has been working for Ca' Foscari in organising the evaluation tests of the qualification courses for secondary education and in supporting the specialisation courses for secondary education. Since 2014 she has been a national observer of evaluation tests in secondary schools and carries out training activities for the Ministero della Pubblica Istruzione, Universita' e Ricerca, Italy. Chiara Urbani has also conducted international research at the Federal University of Minas Gerais (Brazil) on the development of pedagogical professionalism in secondary schools. 